\title{
EL COMERCIO COMO ELEMENTO DETONANTE DEL CRECIMEINTO URBANO: EL CASO DE LA CIUDAD DE BARRANQUILLA'
}

\author{
Artículo de reflexión - Recibido: 2 de Marzo de 2016 - Aceptado: 14 de Mayo de 2016
}

\section{Alberto Gutierrez Lacombe ${ }^{2}$}

SSC Group SAS. Barranquilla - Colombia. algulac@gmail.com

Para citar este artículo / to reference this article:

Gutierrez, A. (2016). El comercio como elemento detonante del crecimeinto urbano: el caso de la ciudad de Barranquilla. Módulo Arquitectura CUC, Vol.17 №1, 145-156.

\section{Resumen}

Este artículo tiene como objetivo esencial el de hacer una reflexión acerca de cómo el comercio, representado por tipologías de centros comerciales y mercados públicos, puede convertirse en un detonador del crecimiento de las ciudades en ciertos casos favorable para los intereses inmobiliarios, pero en otros casos en detrimento del espacio público. Las edificaciones comerciales constituyen una de las primeras formas que diferencian la urbe de lo rural, cambiando el ritmo de vida y convirtiéndose en elementos organizadores del espacio público. Es de suma importancia reflexionar sobre cómo el espacio público responde a las características propias de estas tipologías arquitectónicas comerciales para reconocer si este equipamiento si se constituye como generador adecuado y estructurador de la ciudad.

\section{Palabras clave}

Mercado Publico, centro comercial, diseño urbano, espacio público, desarrollo urbano.

1 Articulo producto de la investigación terminada "El mercado público de Barranquilla como elemento articulador entre la ciudad y su rio." Financiada por la Fundacion I+D+l 2015 


\title{
TRADE AS A DETERMINING ELEMENT OF THE URBAN GROWTH: THE CASE OF THE CITY OF BARRANQUILLA
}

\begin{abstract}
This article has the essential objective of reflecting on how trade, represented by typologies of shopping centers and public markets, can become a detonator of the growth of cities in some cases favorable to real estate interests, but in other cases To the detriment of public space. Commercial buildings are one of the first forms that differentiate the city from the rural, changing the rhythm of life and becoming organizers of public space. It is extremely important to reflect on how the public space responds to the characteristics of these commercial architectural typologies to recognize if this equipment if it is constituted as adequate generator and structurer of the city
\end{abstract}

\section{Keywords}

Public Markets, Malls, urban design, public space, urban development 


\section{Introduccion}

Desde el inicio de las ciudades, el mercado público ha sido un hito importante dentro de la misma y un sitio de encuentro ciudadano. En la edad antigua los mercados, sitios de intercambio y de comercio se planteaban como plazas públicas de alto impacto social: "... que los templos sean edificados cerca de la plaza pública" (Platón, 2003) y además tenían ciertos parámetros a criterios de ubicación. "La plaza pública dispuesta como la Tesalia, se llama plaza de la libertad, no sería jamás mancillada por las mercancías y se prohibirá la entrada de artesanos y a los labriegos, distante de esta plaza, y bien separada de ella, estará la destinada al mercado, el lugar que esta ocupa debe ser fácilmente accesible a todos los transportes que lleguen por el mar o proceden del interior del país" (Platón, 2003). Por esta razón al inicio de la civilización no se puede encontrar un espacio abierto que se pueda llamar un mercado, es quizá porque este espacio era parte del precinto del templo y es solamente más tarde que se encuentra un espacio en la ciudad en la zona de la población común. Los mercados son espacios comerciales que se encuentran en todas las civilizaciones a través del mundo y es donde se compra y se vende en pequeñas cantidades, principalmente alimentos, aunque no únicamente. Es un lugar privilegiado y simbólico para el producto fresco, el cual se encuentra completamente visible para el comprador (Medina, 2013). Pero el desarrollo de estos espacios comerciales se hizo posible gracias al avance del transporte, convirtiéndose en nuevos elementos de la urbe. "En las ciudades de donde tenemos los datos más antiguos, encontramos que las funciones del mercado, "CONSEGUIR, ALMACENAR, DISTRIBUIR, fueron hechas por el templo... Los sumerios representaban el sitio en donde se hacían intercambios comerciales, que en realidad eran intersecciones de caminos era " $Y$ "'" (Mumford, 1961).

La actividad comercial y por consiguiente las edificaciones comerciales han tenido un papel importante de la formación de la ciudad. Más allá de los criterios geográficos y defensivos, la mayoría de las ciudades han crecido y han sido fundadas gracias a las necesidades y los intereses comerciales, las transacciones, los intercambios y el trueque de toda clase de bienes de consumo. La edificación comercial, al igual que las edificaciones religiosas e institucionales dan soluciones a 
determinadas necesidades urbanas y sociales funcionando como apoyo o refuerzo a un determinado equipamiento, o bien por su cualidad como aglutinador urbano (García, 2015).

Las ciudades en sus orígenes habrían sido creadas por la necesidad de consumo y no tanto por la capacidad de producir, lo que significa que el comercio como edificación o lugar es su elemento constitutivo fundamental. En la edad media, el renacer de la ciudad se debió a la aparición del mercader y a las rutas de larga distancia del comercio, al igual que la movilidad obligada de los campesinos hacia el lugar del mercado. Con el auge del gran comercio y con el nacimiento del capitalismo se genera una dinámica mayor en el desarrollo de las ciudades y en consecuencia en la misma forma de la ciudad, que crece alrededor de la edificación del mercado o del comercio (Guardia y Oyon, 2007).

El transporte y la dinámica de flujos generan las calles y la necesidad del comercio e intercambio crea el lugar o la edificación comercial o el mercado como centro urbano ancla de la urbanización, como espacio público y lugar de reunión. (Noguera,
El primer concepto de planificación y diseño de los mercados se dio en la segunda mitad del siglo XVIII, a raíz del nueva ideología social y urbana. Un concepto moderno de ciudad como el embellecimiento de la ciudad no depende de la ornamentación de sus edificios y más por el desarrollo de un sistema integrado de comodidades, basado en la comunicación traslado fácil y segura hacia los lugares importantes. Así que los equipamientos urbanos se distribuían de manera homogénea en la ciudad. Continuaron ideas como la medicalización del espacio urbano la aparición de la admiración pública y la policía configurando de esta manera el pensamiento urbanístico (Guardia y Oyon, 2007).

\section{Comercio como detonador del desarrollo urbano y gestor de espacio publico}

Las exigencias y nuevas dinámicas de la ciudad de competitividad, de rendimiento, de eficiencia, de satisfacción de las necesidades, crearon una red una serie de reglas y de leyes que no dejaron de desarrollar las distintas tipologías arquitectónicas y urbanas en la misma forma. Los edificios de uso comercial adoptaron una funcionalidad que se desarrollaba en tres niveles de organización: El espacio de 
venta, la circulación y en la disposición clasificar las zonas aislándolas del exterior. La distinción del espacio privado y el espacio público se hizo mayor y se unió a la congestión que genera el crecimiento poblacional desmedido para de esa manera vaciar la calle de peatones y llevarlas al interior. Las edificaciones de uso comercial tuvieron mayores exigencias de diseño olvidando lo urbano. Estas tipologías arquitectónicas se convirtieron en el modelo a seguir de espacio comercial y desarrollo urbano, ya que alrededor de este se generan otros usos que lo complementan pero que no son integrados (Guardia y Oyon, 2007).

Los centros comerciales representan cada vez más la idea de la reunión publica en un lugar privado, los usuarios transforman el uso del centro comercial, para ellos no solo es consumo es apropiación de un espacio, se instalan en el espacio del centro comercial y los convierten en lugares."Estos nuevos modos de resguardarse constituyen parte del proceso de des urbanización, a partir del cual cada vez más gente usa menos espacios urbanos o los usa solo en caso de absoluta necesidad. El centro comercial es anti urbano con respecto al contexto inmediato en tanto se constituye en una ínsula que priva- tiza el espacio, lo fragmenta a nivel urbano y a nivel social rompe el tejido social" (Jiménez, Becerra y Olivera, 2009).

El concepto de vida posmoderna promueve la idea de lo individual sobre lo colectivo victimizando de esa manera al espacio público. En la actualidad, el espacio público paso de ser un lugar de intercambio social para convertirse en un espacio de miedo, esto ha creado respuestas acordes a ese sentimiento y responder a la amenaza. La primera respuesta es la del concepto del automóvil privado y la segunda es la creación del centro comercial y de ocio. Ambas soluciones, son conceptos de sistemas cerrados e individualistas y se fundamentan en el dominio de lo privado. El espacio público se convierte solo en una mera circulación, despersonalizando la ciudad y convertirla en un lugar donde el consumo es la prioridad. Los centros comerciales contribuyen con uno de los defectos mayores de la urbe, el cual es la descontextualización. Estas edificaciones se cierran en sí mismos, desvinculándose el contexto, todo lo contrario, a lo que eran los mercados públicos abiertos, los cuales se relacionaban con el entono y el contexto, permitiendo el espacio al aire libre (García, 2015). 
Esta situación a que el espacio público más importante de las ciudades actuales y que no tienen una historia larga sean los centros comerciales. Se han convertido en lugares de encuentro y de apropiación espacial no planeada, aunque su carácter privado coloca en duda si en verdad es público y si todos tienen acceso a él y bajo qué condiciones (Jiménez, Becerra y Olivera, 2009).

Para García Doménech (2015) los centros comerciales son contenedores arquitectónicos, con una estética despersonalizada, que nacen en suelos planificados y sobre la base de la oportunidad económica mas no sobre la necesidad urbana, provocando cierta anti urbanidad, al evitar todo roce con las actividades de la ciudad y con el espacio público que lo limita (García, 2015)

Es cierto que la mayoría de centros comerciales, por lo menos en los países latinoamericanos, no están concebidos para responder al contexto urbano cuando son ubicados dentro de un barrio consolidado. Pero cuando nacen en sitios que no han sido desarrollados pueden generar desarrollos importantes de viviendas y de espacios públicos alrededor de ellos. Estas tipologías se articulan mejor con los flujos de movilidad vehicular que caracterizan los crecimientos suburbanos estructurados en torno al automóvil privado, lo que los convierte en un modelo de gestión económica y social. (García, 2015) Esto resulta completamente cierto en algunas ciudades del tercer mundo, ya que recorrer la ciudad al aire libre es algo complicado por la congestión vial y la gran cantidad de autos, la falta de arborización, parques, falta de aceras amplias y continuas y la falta de cruces peatonales. A diferencia de los centros comerciales en medio oriente y el sudeste asiático, donde poseen tienen funciones diferentes y están siendo diseñados específicamente para cumplir funciones sociales y de ocio y desde la perspectiva de la cultura juvenil, para mujeres jóvenes, artistas y nuevos profesionales estos malls les ofrecen alternativas de interacción en lugares como los cafés pero en un contexto semipúblico e hibrido (Jiménez, Becerra y Olivera, 2009)

Esto nos demuestra que cada civilización urbana estructura de manera específica su espacio alrededor del comercio, y las palabras dan testimonio de ello como lo explica Monnet (1996): "En francés, de alguien muy cortés, alguien que se expresa con mucha civilidad, se dice que es de 
"comercio agradable" (il est d'un agréable commerce)." El comercio, en todo sentido, posee una relación social significativa en una ciudad y dentro del concepto de lo urbano y se convierte en uno de los elementos regulatorios de las relaciones entre lo público y lo privado (o colectividad/individualidad, sociedad/ intimidad). (Monnet, 1996) Las ciudades deben mucho de su crecimiento y evolución al desarrollo de centros comerciales, los cuales se establecen como espacios de relación de las fragmentación de las ciudades que se comunican por medio de autopistas y vías. (Iso, 2013)

En países como Francia, se cuida bastante el valor social de la calle defendiendo el comercio pequeño, del patrimonio histórico y de la estética urbana en contra de las grandes empresas comerciales, aunque esto no impide el fuerte crecimiento de las grandes tiendas bien planeadas. El caso de México es diferente, ya que la calle significa subdesarrollo y el comercio instalado ahí es rechazado. Lo que da pie a la introducción de grandes tiendas comerciales. $Y$ en Estados Unidos, específicamente en California, ya no existe la calle como elemento social urbano son solo ejes de movilidad para acceder a los malls y espacios de comercio cerrados (Monnet, 1996).

\section{Relación del comercio y el desarrollo urbano de Barranquilla}

El primer centro comercial en Colombia se construyó en Medellín en 1972, llamado San Diego y dos años más tarde se construyó Unicentro en Bogotá. De esta manera empezó la construcción masiva de este tipo de edificaciones comerciales, un gran edificio aislado, generalmente en las afueras de la ciudad, al cual se llega en auto y que contaba con grandes áreas de parqueo en el exterior y en su interior un espacio climatizado distintos almacenes. (González, 2010) desde ese entonces se han construido más de 400 centros comerciales en el país a un ritmo de 23 por año y que cada vez abarcan más área. Pero no solo se construyen en ciudades como Bogotá, Medellín y Barranquilla, también en ciudades intermedias como Cartagena, Bucaramanga entre otras. (González, 2010)

El caso específico de Barranquilla, su importancia comercial es indiscutible porque nace, no de un capricho ni de una momentánea y fugaz situación favorable, sino de un cúmulo de circunstancias que hacen de ella la Nueva York de Colombia. Por su condición geográfica es tránsito forzoso del $70 \%$ del tráfico comercial del país 
(Palacio, 2012). "Pero sin buena comunicación entre Barranquilla y el puerto marítimo cercano no era posible que la ciudad se consolidará como centro comercial e industrial." (López, 2014) Esto la transformó de pequeña aldea a una ciudad, con un trazado irregular que poco a poco fue cambiando. Al ser una ciudad de carácter comercial su mercado público fue actor principal de ese cambio y el resultado de la proyección y planteamiento del General José Félix Fuenmayor Parra, un hombre nacido en Maracaibo en 1827, que además de desempeñar una exitosa carrera como militar, también fue un filántropo y un hombre cívico. (López, 2015)

En materia de construcción, las cifras de centros comerciales cada vez más, van en aumento. $Y$ es que al día de hoy son 207 los complejos construidos en el país, que tienen más de $5.000 \mathrm{~m}^{2}$ de GLA -superficie comercial útil-, de los cuales existen 26 en la Región Caribe y de estos 13 están solo en Barranquilla. Carlos Hernán Betancourt, director ejecutivo de la Asociación de Centros Comerciales de Colombia -Acecolombia-, confirma que a la fecha, la totalidad de estos complejos en el país representan cerca de $4.498 .598 \mathrm{~m}^{2}$ de área comercial.Explica además que, en comparación con el año anterior, se registraron cinco nuevas aperturas que equivalen a $108.462 \mathrm{~m}^{2}$. Betancourt asegura que, después de Bogotá con 52 complejos que aportan 1.378.936 $\mathrm{m}^{2}$ de área comercial, en la Región Caribe, Barranquilla es la ciudad con mayor número de centros comerciales (Cano, 2015).

En Barranquilla se construyó Almacenes Sears, una cadena multinacional que el 5 de marzo de 1953. Este almacén introdujo en Colombia a principio de los 50 una nueva cultura para el desarrollo de las de las actividades comerciales, aunque no era un centro comercial, si introdujo la idea de la gran tienda en la por su gran tamaño y en un mismo local espacioso le ofrecieran al consumidor desde muebles para el hogar hasta un supermercado. El concepto del parqueadero era visionario y casi nunca llegaba a llenarse por completo. Este gran almacén era el único que tenía climatización y escaleras eléctricas. Era cerrado con grandes vitrinas y múltiples entradas con una pequeña plaza de acceso por la entrada principal, la mayoría de personas llegaban en bus. Alrededor de este almacén se construyeron torres de 15 pisos residenciales con comercio en primer piso. Luego en los 
años 80 se construyó el centro comercial Gran Centro, ubicado en la calle 70 con carrera 53, en una zona que ya estaba consolidada cerca de la calle 72 que se convirtió en avenida importante comercial de locales aislados y los cuales eran accesibles por la acera peatonal. Lo que parecía más fácil que entrar a parquear y buscar almacenes adentro. Barranquilla, continúo creciendo hacia el norte y en el año 2001 se construyó el centro comercial Buenavista en una zona a las afueras de la ciudad, en la calle 98 con carrera 53, el desarrollo urbano llegaba hasta la calle 94 y en algunos casos hasta la calle 96. Alrededor, eran lotes que sirvieron de canteras para cementeras locales, pero a raíz de este centro comercial se generó todo un desarrollo de proyectos residenciales y comerciales y que después de 15 años las vías proyectadas no dan abasto para el flujo vehicular existente.

\section{Conclusiones}

Los edificios de uso comercial han condicionado el desarrollo de la ciudad, desde el punto de vista de crecimiento económico y en su traza ya que generan ejes y corredores de movilidad. De igual forma cobra relevancia el tipo de urbe donde se desarrolla el comercio la cual debería desarrollarse bajo parámetros de planeación y una mínima estructura urbanística, puesto que, si no existe control el edificio comercial generara un impacto inmediato posiblemente negativo en su entorno (Baquero, 2011).

Las tipologías comerciales para la población, densifican el uso del espacio público y la movilidad urbana, generan congestión, contaminación ambiental alrededor de su entorno mediato e inmediato; estas tipologías deben estar consignados en los tratamientos urbanos desde el enfoque del diseño urbano y de esa manera corregir conflictos y proporcionar las condiciones apropiadas para mejorar los entornos y el potencial de estos sectores como núcleos de centralidad zonal (Baquero, 2011).

Estas tipologías influencian sobre manera el desarrollo de las ciudades, y "ha convertido al mall en el modelo a seguir por las zonas comerciales urbanas, muchas de ellas en recesión tras ser extirpadas de gran parte de la vida social, absorbidas precisamente por el mall, aunque claramente desvirtuada" (Toro, 2009) La situación es compleja. Los espacios públicos dedicados al comercio están transformando y definiendo la trama urbana, 
estos espacios generalmente se adaptan rápidamente a la demanda y las funciones sociales cambiantes. Es precisamente estas capacidades de flexibilidad y adaptabilidad, han llevado a tomar centros comerciales como un modelo de generación de espacio público y de renegociación social (Medina, 2013) pero de teniendo cuidado de que sea forma sostenible, ya que las oportunidades comerciales de la urbe no son infinitas y requieren de gestión que planifique su sobreexplotación, un uso comercial descontrolado puede quemar la ciudad (García, 2015).

Uno de las grandes ventajas de los centros comerciales es el hecho de que el ser urbano disfruta ver a los demás y observar sus actividades, lo que resulta de mayor interés y llama más la atención que otras actividades que se dan en la calle. "La otra gente es el verdadero espectáculo que se viene a disfrutar. Es así como se apropian sustitutivamente de los centros comerciales y con su comportamiento social los transforman en lugares más porosos a pesar del diseño original dirigido al consumo, la normatividad y la vigilancia y se pueden adoptar comportamientos típicos de espacios abiertos como los parques transgrediendo la centro comercial" (Jiménez, Becerra y Olivera, 2009) Otra gran ventaja, es la representación de ciudad ideal que manejan estas tipologías. "Un espacio seguro, de encuentro entre iguales en la medida en que todos son consumidores y todos van a consumir y de sorpresas agradables y calculadas. El espacio de encuentro y compras que antes se situaba en espacio público del centro de la ciudad. Esta ciudad ideal para el consumo del centro comercial suburbano, periférico, ha terminado por configurarse, en un segundo momento, como un modelo para la construcción de la ciudad misma" (Iso, 2013) De esta manera la ubicación de centros comerciales en zonas en las cuales se necesita renovar o regenerar el espacio urbano es una lógica opción y puede lograr imaginarios urbanos diferentes. De ahí que la implantación de nuevos centros comerciales cerrados y privados en el interior de las ciudades genera una nueva orientación y un nuevo diseño del espacio público, siempre facilitando la circulación hacia ellos (Iso, 2013).

Como lo expresa González (2010) los centros comerciales cumplen un papel transformador y de referencia en la ciudad haciendo una presencia fuerte arquitectónica y urbanística innegable y continua explicando: "como lo 
señalan los mismos arquitectos en el encuentro de 1996, "constituyen uno de los fenómenos arquitectónicos y metropolitanos más poderosos y determinantes de los últimos veinte años"; pero, aun así, según lo plantea Bauman (2003) en su libro Modernidad líquida, son espacios públicos no civiles, que no están diseñados para la práctica individual y plena de la civilidad, ni tampoco son un bien común, sino, fundamentalmente, espacios para "convertir al residente de la ciudad en un consumidor" (Gonzalez, 2010).

\section{Referencias}

Baquero, D. (2011). Las plazas de mercado como catalizadores urbano. Bogotá, D.C.: Universidad Nacional de Colombia.

Bauman, Z. (2003). Modernidad líquida. México, D.F.: FCE.

Garcia S. (2015). Espacio público y comercio en la ciudad contemporánea. Dearq, 26-39.

Gonzalez, L. F. (2010). Los centros comerciales o el simulacro del espacio público. Agenda Cultural.

Guardia, M., \& Oyon, J. (2007). Los mercados públicos en la ciudad contemporanea. El caso Barcelona. Barcelona.
Iso, A. (2013). El espacio público en los centros comerciales a cielo abierto. El caso de Pamplona. Zainak, 213-230.

Jimenez, B., Becerra, O., \& Olivera, A. R. (2009). Apropiación pública del espacio en centros comerciales de la zona metropolitana de Guadalajara. Medio Ambiente y Comportamiento Humano, 253-285.

Lopez, J. (2015). El mercado público de Barranquilla entre 1880-1888. Memorias, 25-41.

Lopez, J. (2014). Eco renovación urbana del borde de la ciudad de Barranquilla que limita con el del río Magdalena. Modulo Arquitectura CUC, 255-271.

Medina, F. X. (2013). Mercados y espacio público:transformación y renegociación de nuevas demandas urbanas. Zainak, 183-200.

Monnet, J. (1996). Espacio público, comercio y urbanidad en Francia, México y Estados Unidos. Alteridades, 11-25.

Mumford, L. (1961). The city in the history. It's origins, it's transformation and prospect. San Diego: Harcourt, Brace \& World. 
Noguera, J. (2011). Modelo barcelona: diseño urbano y espacio publico. La peatonalizacion alrededor de los mercados municipales del siglo XIX. Barcelona: Universidad de Barcelona.

Palacio, B. (2012). Barranquilla y el Período Republicano Mercantil. Modulo Arquitectura CUC, 145-169.
Platon. (2003). Dialogos.Obra completa en ) volumenes. Madrid: Editorial Gredos.

Toro, F. (2009). Los centros comerciales. espacios postmodernos de ocio y consumo. Cuadernos de Geografia, 257-261. 